\title{
Das utopias que se tornam realidade, ou: sobre homens que trabalham com feminismos*
}

\begin{abstract}
Ramon Pereira dos Reis**
O problema da questão de gênero é que ela prescreve como devemos ser em vez de reconhecer como somos. Seríamos bem mais felizes, mais livres para sermos quem realmente somos, se não tivéssemos o peso das expectativas de gênero (Adichie, 2014).
\end{abstract}

Desde as formulações clássicas de Simone de Beauvoir (2009 [1949]) sobre a força político-identitária da categoria mulher e do quanto essa identificação é transitória e situacional, até os escritos de Judith Butler (2003) a respeito da desestabilização do termo gênero, a partir do confronto com uma determinada matriz de inteligibilidade sexual, já se passaram 66 anos, levando em conta os dias atuais.

Do ponto de vista do feminismo, enquanto marcação acadêmica, temporal e política, percorremos, ao longo desses anos, algumas vertentes balizadas pelos estudos feministas e de gênero, que, conforme o tempo, tornaram cada vez mais próxima a relação entre militância e academia, quais sejam: "feminismo socialista", "feminismo radical" e "feminismo global" (Piscitelli,

\footnotetext{
* Recebida para publicação em 29 de outubro de 2015, aceita em 4 de dezembro de 2015. Resenha de MEDRADO, Benedito; LYRA, Jorge. Produzindo memórias para alimentar utopias: Narrativas sobre uma organização feminista brasileira que, desde 1997, ousa trabalhar com homens e sobre masculinidades. Recife, Instituto PAPAI, 2015. Agradeço o cuidado que Ronney Alano Reis teve durante sua revisão gramatical do texto.

** Doutorando em Ciência Social (Antropologia Social), Universidade de São Paulo (USP), São Paulo, SP, Brasil, com bolsa Fapesp. ramonrei@gmail.com 
2002), além daquela que há algum tempo demanda pautas mais detidas no entrecruzamento de raça, classe e sexualidade, a exemplo do feminismo negro (hooks, 1981; Davis, 1983; Collins, 1990). Um dos elos que une tais feminismos é que a grande maioria, se não todos, são protagonizados por mulheres.

É possível, então, ser homem feminista, ou ser homem $e$ trabalhar com feminismos? Como articular a(s) pauta(s) feminista(s) aos estudos sobre homens e masculinidades? Com o intuito de percorrer tais questionamentos é que Benedito Medrado e Jorge Lyra (2015), psicólogos e fundadores do Instituto PAPAI (Programa de Apoio ao Pai) e do Núcleo de Pesquisas em Gênero e Masculinidades (GEMA) - ambos vinculados à Universidade Federal de Pernambuco (UFPE) -, produzem memórias e alimentam utopias em torno da recuperação de narrativas sobre uma organização feminista brasileira que, desde 1997, ousa trabalhar com homens e sobre masculinidades, como assim intitulam o livro que celebra a maioridade do PAPAI, e cujas memórias servem de aporte explicativo a respeito do jogo político cotidiano que ocorre dentro e fora da universidade.

Trata-se de um livro em tom de memorial, composto por um prefácio, uma introdução, 12 pequenos capítulos (que compreendem a história, os projetos de desenvolvimento $e$ visibilidade, até os objetivos de missão e gestão da organização), um posfácio (escrito por duas mulheres e dois homens que integram a equipe do PAPAI) e um registro fotográfico com uma seleção de imagens dos eventos mais emblemáticos, cuja intenção é

[...] registrar os acontecimentos e pessoas que tornaram essa história uma produção coletiva e um empreendimento compartilhado com vários/as em diferentes ocasiões $e$ desafios. Não estamos aqui preocupados com o conteúdo, mas com os processos. Não estamos preocupados em sermos "fiéis aos fatos" porque não partimos de uma leitura realista sobre memória. $\mathrm{O}$ que nos comprometemos aqui foi, sobretudo, em fazer um exercício de (re)cordar e refletir criticamente sobre nossas escolhas, decisões e possíveis 
erros, colocando em suspensão e suspeição as ideias que acreditamos e defendemos (p.16).

Ressalto que, assim como os autores, não estou interessado em uma construção textual linear e que por isso darei ênfase ao processo de construção da organização, seu raio de desenvolvimento e ação, e os efeitos de sua permanência no cenário nacional dos estudos feministas e de gênero. Noto ainda que, do mesmo modo que existe uma funcionalidade e uma seleção dos eventos que terão lugar no livro, não posso deixar de perceber que esse exercício de recuperação de dados e de situações está sempre envolto da relação dialógica entre indivíduo e coletividade, passível das transformações do tempo (Cf. Halbwachs, 2006), e que também localiza a(s) memória(s) e a(s) identidade(s) como valores em constante disputa (Cf. Pollak, 1992).

Ao longo desses 18 anos de existência do Instituto PAPAI fica evidente, na composição da trajetória dessa organização, seu importante potencial enquanto disseminadora e multiplicadora de conhecimento dentro e fora da UFPE. Ressalto as articulações do PAPAI com organizações e grupos, em âmbito nacional $e$ internacional, que atuam na publicação de conteúdos sobre gênero, sexualidade, saúde sexual, e no combate a violências de gênero e por orientação sexual: ECOS, Promundo, Núcleo Margens/UFSC, Fundação Carlos Chagas, Núcleo de Estudos de Gênero Pagu/Unicamp, Faculdade de Medicina da USP, Grupo de Pesquisa NósMulheres. Pela equidade de gênero étnicoracial/UFPA, entre outras.

$\mathrm{O}$ percurso histórico que sistematiza e sustenta o argumento central do livro garante, do início ao fim, o protagonismo e o reconhecimento à(s) figura(s) da(s) mulher(es), bem como leva em conta o importante papel dos estudos feministas e de gênero enquanto referências para a consolidação do PAPAI. Não se trata, assim, de uma instituição que invisibiliza lutas ou que pretende ser porta-voz da militância feminista. Nesse sentido, não há como negar 
que os feminismos criaram modos específicos de existência mais integrados e humanizados, desfazendo as oposições binárias que hierarquizam razão $e$ emoção, público $e$ privado, masculino e feminino, heterossexualidade $e$ homossexualidade (Rago, 2013:27).

Medrado e Lyra creditam à Fúlvia Rosemberg (in memoriam) educadora com formação em psicologia social, pesquisadora $e$ militante da causa feminista - o importante papel de incentivadora para que ambos pudessem fundar o PAPAI e o GEMA, além de ela ter servido de inspiração para que eles começassem a trabalhar efetivamente com as temáticas sobre homens e masculinidades dentro da perspectiva do campo de conhecimento supracitado.

A construção textual irá se sustentar sobre dois pilares: a emoção, menos de uma "emoção raciocinada" (Miceli, 2005) que age como disciplinadora de afetos, mas como uma pletora de significados e de sensações agenciadas pelo raciocínio e sobretudo pelo coração; e a política (cotidiana). A partir dessa chave é possivel compreender sobre qual tripé se assenta o PAPAI e a maneira como produz ativismos dentro e fora da academia. Desse modo, o ensino, a pesquisa, e a intervenção política comunitária irão se associar ao que os autores concebem como tríade temporal de interação, vivência e duração como formas de produzir, repassar e publicar conhecimento. Foi preciso, acima de tudo, de uma articulação efetiva entre teoria e prática para que esse projeto pudesse se tornar palpável.

$\mathrm{Na}$ esteira do comprometimento acima, a idealização do Núcleo de Pesquisas em Gêneros e Masculinidades (GEMA), sediado na UFPE, se mostrou uma poderosa ferramenta de suporte e visibilidade, principalmente porque o núcleo está formalmente vinculado ao Conselho Nacional de Desenvolvimento Científico e Tecnológico (CNPq), desde 1998, mesmo ano de sua fundação. Além de formar uma série de pesquisadoras/es, em nível de graduação, mestrado e doutorado, a atuação junto à população em geral ganhou fôlego por meio das seguintes linhas de pesquisa: 1 Saúde, sexualidade e reprodução; 2 - Homens, masculinidades e 
contextos sociais; 3 - Teoria feminista: conceitos e implicações políticas e 4 - Experiências geracionais e a construção social das categorias etárias.

As marcações sociais de cada uma das linhas de pesquisa acima remontam ao que Adriana Piscitelli (2002) irá chamar de "feminismos globais" que procuram trazer à baila o debate da produção social das diferenças (Brah, 2006) pela via das articulações entre gênero, sexualidade, raça, classe (McClintock, 2010), dentre outras. Nota-se que esse caráter global articulará demandas locais de pesquisa ampliando panoramas específicos em torno de perspectivas transnacionais que não se resumem à desigualdades e/ou superposições.

Outro ponto fundamental que atuará a favor do entendimento do porque o PAPAI e o GEMA podem ser consideradas organizações feministas, e, consequentemente, dos modos sobre os quais determinadas pautas feministas podem ser desenvolvidas por homens, refere-se ao compromisso e respeito com que Medrado e Lyra circulam e se inserem nesse campo. A entrada na Rede Feminista Norte-Nordeste de Estudos e Pesquisas sobre Mulher e Relações de Gênero (REDOR), em 1999, por ocasião do $9^{\circ}$ Encontro da Rede, realizado em Fortaleza, é um bom exemplo disso. Diante dessas vicissitudes, eles comentam:

Obviamente, nossa aproximação com o movimento feminista nem sempre foi tranquila. Apesar do respeito $e$ cuidado de algumas colegas, especialmente Ana Alice Costa e Luzia Miranda Álvares, entre outras, em diferentes momentos, na REDOR, fomos, direta ou indiretamente, motivo de desconforto quando nossos nomes eram sugeridos para ocupar algum lugar de representação da Rede. Mas, isso não aconteceu somente na REDOR. Muitas foram as situações em que fomos questionados sobre nosso trabalho. Havia as que não entendiam ou não queriam entender nossa proposta. Porém, na grande maioria das situações houve acolhimento $e$ a compreensão compartilhada sobre a importância e necessidade de maior 
envolvimento de homens em questões relativas à saúde e à vida reprodutiva (p.55).

Lembro que na reconstituição que Bourdieu (2005) faz de sua trajetória acadêmica, ele também mostra como a formação de campos de conhecimento e de atuação passam por perspectivas de tensão e conflito nas quais entram em jogo proximidades $e$ distanciamentos que dependem do manejo de habitus específicos; nas palavras dele:

O efeito de campo exerce-se em parte por meio do confronto com as tomadas de posição de todos ou de parcela daqueles que também estão engajados no campo ( $e$ são outras encarnações distintas, e antagônicas, da relação entre um habitus e um campo: o espaço dos possíveis realiza-se nos indivíduos que exercem uma "atração" ou uma "repulsão", a qual depende do "peso" deles no campo, isto é, de sua visibilidade, e da maior ou menor afinidade dos habitus que leva a achar "simpáticos" ou "antipáticos" seu pensamento e sua ação (Bourdieu, 2005:55).

Nesse sentido, a aproximação mais direta com os movimentos feministas regional $e$ nacional se mostrou uma estratégia válida para dar solidez à organização, embora nunca tivessem buscado exclusividade nesse contexto. Nas palavras deles: "[...] Nunca pleiteamos estar em espaços exclusivamente destinados às mulheres e sempre consideramos que estes espaços exclusivos, embora não fossem desejáveis, eram plenamente estratégicos e necessários" (p.57-58). Tais atuações os fizeram compreender que padrões "hegemônicos" de masculinidades e de feminilidades não se sustentam, além de entenderem que não é possível ser uma organização feminista que se propõe a trabalhar com homens e sobre masculinidades sem reconhecerem o papel crucial das mulheres, feministas ou não, nesse processo histórico de lutas e conquistas de direitos. 
Foram muitas as mulheres que serviram de estimuladoras $e$ inspiradoras para a continuidade do PAPAI, são elas: Sônia Correa, Ana Alice Costa, Margareth Arilha, Sônia Malheiros Miguel, Lilián Abrascinskas, Roxana Vazquez, Verena Stolcke, Nilza Iraci, Suely Carneiro, Edna Roland, Estela Aquino, Jaqueline Pitanguy, Simone Diniz, Débora Diniz, Suely Oliveira, Gigi, Ana Bosh, Vera Baroni, Vanete Almeida, e Maria Betânia Ávila, que também presidiu o conselho do PAPAI por alguns anos. Vale mencionar que atualmente a coordenação geral do Instituto é de uma mulher, Mariana Azevedo.

O fortalecimento dessas redes locais, regionais, nacionais $e$ internacionais, ao mesmo tempo em que auxiliou no processo de amadurecimento tanto do PAPAI quanto do GEMA, também tonificou a produção de conhecimento em gênero e sexualidade nas regiões norte e nordeste. Infelizmente, esse é um aspecto que acabou ficando de fora da narrativa dos autores. Mesmo que eles tenham comentado de maneira pontual os esforços, individuais $e$ coletivos, em formar um contingente de pesquisadoras/es que trabalhem com essa temática. Trata-se de uma reflexão que não ganhou força na seleção das memórias, e que necessitaria, no mínimo, de um capítulo.

O diálogo entre academia e militância é outra chave importante para a construção do livro. Essa é uma via de análise que irá se dar pela circulação e participação das/dos pesquisadoras/es que integram o PAPAI e o GEMA em eventos nacionais $e$ internacionais $e$ do envolvimento em campanhas tanto on quanto off line. Essa relação será mais fortemente esquadrinhada da metade para o final do texto com vistas a lançar olhar para o caráter de gestão e a própria missão das organizações referidas.

Do período de 1999 aos dias atuais, uma série de inserções foram importantes para o reconhecimento, a visibilidade $e$ o consequente amadurecimento do Instituto em torno da temática das drogas, dos direitos humanos e sexuais, do HIV/IST/Aids, da saúde pública. Cito os seguintes eventos e organizações que tiveram lugar nesse processo de consolidação: Seminário 
Itinerante Latino-Americano (SILA), I Conferência Internacional sobre Consumo de Álcool e Redução de Danos, Programa Nacional de DST/Aids, Associação Brasileira de Psicologia Social (ABRAPSO), Associação Brasileira de Redutoras e Redutores de Danos (ABORDA), Programa $\mathrm{H}$, Seminários Brasileiros sobre Homens e Masculinidades. Além, sobretudo, de participarem das seguintes campanhas: Machismo não combina com saúde. Por uma atenção integral à saúde dos homens; Campanha do Laço branco: Homens pelo fim da Violência contra a Mulher; Paternidade: Desejo, Direito e Compromisso; Pai não é visita! Pelo direito de ser acompanhante no pré-natal, parto e pós-parto; Dá licença, eu sou pai! Pela ampliação da licença paternidade. Machismo não combina com Saúde!; A Diversidade é Legal! Pela promoção da livre sexualidade e de expressões de gênero e, Amor Livre! Pelo fim da homofobia; estas duas últimas refletem a atuação direta do PAPAI e do GEMA na organização das Paradas do Orgulho LGBT de Recife.

As iniciativas mencionadas mostram a expressiva atuação das/dos pesquisadoras/es de maneira que suas práxis políticas não se circunscrevem ao espaço da universidade. Nesse sentido, mesmo que indiretamente, a narrativa que é construída nos auxilia a pensar metodológica e estrategicamente o que devemos fazer para garantirmos rentabilidade à(s) nossa(s) presença(s) em espaços onde somos vistos, inicialmente, como outsiders; quais as alianças devemos estabelecer; e tantas outras questões que irão definir, a longo prazo, nossa posição enquanto sujeitos do conhecimento. É sobre essa perspectiva textual que o livro é finalizado. A partir dos breves depoimentos de Mariana, Thiago, Regina e Sirley, presentes no posfácio, sobre suas distintas entradas no PAPAI, é possível perceber a emoção e a política se renovando, ou melhor, sendo oxigenadas por meio da transparência, confiança, compromisso, respeito e humor princípios básicos da organização.

À guisa de conclusão, esse é um livro importante para o campo de estudos feministas e de gênero não somente porque trata de modo sistemático como articular militância e academia a 
partir dos processos de constituição de uma organização feminista que ousa trabalhar com homens e sobre masculinidades, assim como por se comprometer em desmistificar que o conceito de "masculinidade hegemônica" (Connell, 1995) nada mais é que um arquétipo precário de representação; garantindo, então, que um amplo debate se instaure sobre homens, masculinidades, saúde sexual do(s) homem(ns) etc., e, portanto, possibilitando que homens, reconhecendo o pioneirismo das lutas feministas, possam, ainda que nem todos se identifiquem enquanto feministas, se aventurar e ousar trabalhar com feminismos.

Desta feita, "feminista é o homem ou a mulher que diz: 'Sim, existe um problema de gênero ainda hoje e temos que resolvê-lo, temos que melhorar'. Todos nós, mulheres e homens, temos que melhorar" (Adichie, 2014:35). Afinal, como alertam Medrado e Lyra: não se nasce homem, torna-se homem. Desse modo, é notável o ganho epistemológico e prático que o livro apresenta a respeito da relação $e$ da inserção de homens que ousam trabalhar com feminismos dentro do campo dos estudos de gênero e sexualidade e, sobretudo, da militância feminista.

\section{Referências bibliográficas}

ADICHIE, Chimamanda Ngozi. Sejamos todos feministas. São Paulo, Companhia das Letras, 2014.

BEAUVoIR, Simone de. O segundo sexo - volume único. Rio de Janeiro, Editora Nova Fronteira, 2009. [1949].

BourdiEU, Pierre. Esboço de auto-análise. São Paulo, Companhia das Letras, 2005.

BRAH, Avtar. Diferença, diversidade, diferenciação. Cadernos Pagu (26), Campinas-SP, Núcleo de Estudos de Gênero-Pagu/Unicamp, jan./jun. 2006, pp.329-376.

BUTLER, Judith. Problemas de gênero - Feminismo e subversão da identidade. Rio de Janeiro, Civilização Brasileira, 2003. [1990]. 
490 Das utopias que se tornam realidade

COLLINS, Patricia Hill. Black Feminist Thought: Knowledge, Consciousness and the Politics of Empowerment. New York, Routledge, 1990.

CONNELL, Robert. Masculinities. Berkeley, CA, University of California, 1995.

Davis, Angela. Women, Race and Class. United States, Random House, 1983.

HalBWACHS, Maurice. A memória coletiva. São Paulo, Centauro, 2006.

HOOKS, bell. Ain't I a Woman?: Black women and feminism. United States, South end Press, 1981.

MCCLINTOCK, Anne. Couro Imperial - Raça, gênero e sexualidade no embate colonial. Campinas-SP, Editora da Unicamp, 2010.

MICELI, Sergio. Introdução. In: BOURDIEU, Pierre. Esboço de auto-análise. São Paulo, Companhia das Letras, 2005, pp.7-20.

PISCITELli, Adriana. Recriando a (categoria) Mulher?. In: AlgRANTI, Leila (org.). A prática feminista e o conceito de gênero. Textos Didáticos, $\mathrm{n}^{\circ}$ 48, Campinas-SP, IFCH - Unicamp, 2002, pp.7-42.

POLLAK, Michael. Memória e Identidade Social. Estudos Históricos, Rio de Janeiro, vol. 5, n 10, 1992, pp.200-212.

RAGO, Margareth. A aventura de contar-se: feminismos, escritas de si e invenções da subjetividade. Campinas-SP, Editora da Unicamp, 2013. 